\title{
Concentrações de BAP sobre a proliferação in vitro de brotos de Lippia alba [(Mill.)N.E.Brown]
}

\author{
ASMAR, S.A.*; RESENDE, R.F.; ARARUNA, E.C.; MORAIS, T.P.; LUZ, J.M.Q. \\ Universidade Federal de Uberlândia - UFU, Instituto de Ciências Agrárias, Campus Umuarama, Av. Amazonas s/n, \\ CEP: 38400-902, Uberlândia-Brasil *siasmar@yahoo.com.br
}

\begin{abstract}
RESUMO: Lippia alba é uma planta de origem brasileira, pertencente à família Verbenaceae. É conhecida por combater a insônia e a asma, além de possuir ação anticonvulsivante e antifúngica. A micropropagação tem sido utilizada para multiplicação de várias espécies com propriedades medicinais, e o BAP é a citocinina sintética mais utilizada para a multiplicação in vitro. O objetivo deste trabalho foi estabelecer a concentração adequada de BAP na multiplicação in vitro de $L$. alba. Explantes constituídos de segmentos nodais provenientes de plântulas já estabelecidas in vitro com aproximadamente $0,5 \mathrm{~cm}$ foram inoculados em meio MS, suplementado com 0,$0 ; 0,5$; 1,0 e 1,5 mg L-1 de BAP em adição de $30 \mathrm{~g} \mathrm{~L}^{-1}$ de sacarose. A utilização de 1,5 $\mathrm{mg} \mathrm{L}^{-1}$ de BAP promove a multiplicação in vitro de $L$. alba. A ausência deste regulador propicia maior número de folhas e o uso na concentração de $0,5 \mathrm{mg} \mathrm{L}^{-1}$ aumentou as massas fresca e seca de parte aérea nesta espécie.
\end{abstract}

Palavras-chave: cultura de tecidos, regulador de crescimento, plantas medicinais

\begin{abstract}
BAP concentrations on in vitro proliferation of Lippia alba [(Mill.) N.E.Brown] shoots. Lippia alba is a Brazilian plant, belonging to the Verbenaceae family. It is known to combat insomnia and asthma, also has antifungal and anticonvulsant actions. Micropropagation has been used for propagation of various species with medicinal properties, and BAP is the most widely used synthetic cytokinin for in vitro multiplication. The aim of this study was to determine the appropriate concentration of BAP on in vitro multiplication of $L$. alba. Explants consisting of nodal segments from seedlings already established in vitro with approximately $0.5 \mathrm{~cm}$ were inoculated on MS medium supplemented with $0 ; 0.5 ; 1.0$ and $1.5 \mathrm{mg} \mathrm{L}^{-1}$ of BAP and $30 \mathrm{~g} \mathrm{~L}^{-1}$ of sucrose. The use of $1.5 \mathrm{mg} \mathrm{L}^{-1}$ of BAP promotes the in vitro multiplication of $L$. alba. The absence of this regulator provides a greater number of leaves and its use at the concentration of $0.5 \mathrm{mg} \mathrm{L}^{-1}$ increased shoots' fresh and dry weights in this specie.
\end{abstract}

Key words: tissue culture, growth regulator, medicinal plants

\section{INTRODUÇÃO}

A espécie Lippia alba [(Mill.) N.E. Brown] é uma planta de origem brasileira_distribuída em regiões de clima tropical, sub-tropical e temperado. Pertence à família Verbenaceae, vegeta em solos arenosos e nas margens de rios, açudes, lagos e lagoas. Conhecida popularmente como alecrim, alecrim do mato, alecrim do campo, camará, capitão do mato, cidrão, cidreira, cidreira brava, capim cidreira, cidreira crespa, cidreira falsa, cidreira melissa, erva cidreira, erva cidreira do campo, erva cidreira brasileira, falsa melissa, salva do Brasil, salva limão e outras denominações (Ming, 1992).

É uma planta indicada como antiespasmódico, estomáquico, carminativo e calmante. Combate ainda a insônia e a asma (Martins et al., 2000). Possui ação anticonvulsivante e antifúngica (Rao et al., 2000).

Embora as plantas do gênero Lippia sejam fontes de importantes compostos biologicamente ativos, as informações científicas sobre seus métodos de propagação crescem em ritmo pouco intenso. Portanto, torna-se imprescindível a realização de estudos mais aprofundados de âmbito farmacológico, terapêutico e agronômico, para o cultivo em larga escala e a conservação desta espécie.

Estudos de germinação de sementes em espécies de Lippia são escassos na literatura

Recebido para publicação: setembro de 2011

Aceito para publicação: março de 2012

Rev. Bras. PI. Med., Botucatu, v.14, n.esp., p.149-153, 2012. 
(Pimenta et al., 2007; Blank et al., 2008) e trabalhos relacionados à propagação vegetativa convencional apontam baixos percentuais de enraizamento e de sobrevivência de mudas produzidas a partir de estacas (Capote et al., 1999; Juliani Júnior et al., 1999). Visto isto, a propagação in vitro apresenta grande potencial para multiplicação em massa e perpetuação de plantas de L. alba.

A micropropagação é um método alternativo de propagação vegetativa amplamente estudado nas mais diversas espécies vegetais, sendo a técnica dentro da cultura de tecidos que mais tem difundido e encontrado aplicações práticas comprovadas. Entre as vantagens da utilização, estão a possibilidade de obterem-se várias plantas a partir de um explante inicial, independentemente da estação do ano; a redução do tempo e da área necessária à propagação da espécie; as melhores condições sanitárias; a reprodução do genótipo da planta-mãe, com fidelidade durante a multiplicação e a propagação vegetativa de espécies difíceis de serem propagadas por outros métodos (Erig \& Schuch, 2005).

Desta forma, a micropropagação tem sido utilizada para multiplicação de várias espécies com propriedades medicinais, para que destas, também possam ser extraídos óleos essenciais, uma vez que estas mudas apresentam elevada qualidade genética e fitossanitária. Com relação ao cultivo in vitro do gênero Lippia, alguns trabalhos já foram realizados com resultados satisfatórios (Capote et al., 1999; Gupta et al., 2001; Peixoto et al., 2006; Costa et al., 2007).

Um dos principais fatores que interferem na propagação in vitro é a suplementação do meio de cultivo com reguladores de crescimento vegetal. As citocininas são uma classe de reguladores com capacidade marcante de induzir a divisão celular em tecidos vegetais. Portanto, são importantes para formação de órgãos, principalmente aéreos. A benzilaminopurina (BAP) é uma citocinina sintética utilizada para a multiplicação in vitro de diversas espécies (Lucas et al., 2007).

O objetivo deste trabalho foi estabelecer a concentração adequada de BAP na multiplicação in vitro de Lippia alba.

\section{MATERIAL E MÉTODO}

O trabalho foi realizado no Laboratório de Biotecnologia da Universidade Federal de Uberlândia. Segmentos nodais provenientes de plântulas já estabelecidas in vitro com aproximadamente $0,5 \mathrm{~cm}$ foram inoculados em meio MS (Murashige \& Skoog, 1962), suplementado com $30 \mathrm{~g} \mathrm{~L}^{-1}$ de sacarose e BAP nas concentrações de 0,0; 0,5; 1,0 e 1,5 $\mathrm{mg} \mathrm{L}^{-1}$.

$\mathrm{O} \mathrm{pH}$ do meio de cultura foi ajustado para 5,8 e em seguida autoclavado a $121^{\circ} \mathrm{C}$ e $1,2 \mathrm{~atm}$ durante 20 minutos. Posteriormente em câmara de fluxo laminar, os explantes foram inoculados em frascos de $200 \mathrm{~mL}$, contendo $30 \mathrm{~mL}$ do meio de cultura MS. Os frascos foram vedados com tampas de polipropileno e mantidos em sala de crescimento convencional, com fotoperíodo de 16 horas de luz, temperatura de $25 \pm 2^{\circ} \mathrm{C}$, com intensidade de $52,5 \mathrm{~W}$ $\mathrm{m}^{-2} \mathrm{~s}^{-1}$, fornecida por lâmpadas brancas fluorescentes.

O delineamento experimental foi 0 inteiramente casualizado, com quatro tratamentos consistindo de 10 frascos cada um, sendo que cada frasco continha quatro explantes. Os dados obtidos foram submetidos à análise de variância utilizandose o programa estatístico Sisvar 4.3 (Ferreira, 2000), utilizando-se o teste de regressão a $5 \%$ de significância.

Após 60 dias foram avaliadas as seguintes características: índice de sobrevivência (número de explantes desenvolvidos por número de explantes inoculados), número de folhas, número, comprimento, massa fresca e seca das brotações desenvolvidas.

\section{RESULTADO E DISCUSSÃO}

Não houve diferença significativa para a variável índice de sobrevivência (Tabela 1). Em todos os tratamentos as plântulas apresentaram taxa de sobrevivência superior a $80 \%$. Nargis et al. (2010), por outro lado, verificaram que a regeneração de explantes de Lippia javanica [(Burm.f.) Spreng.], inoculados em meio MS, foi máxima $(100 \%)$ apenas nos tratamentos com a presença do BAP, independentemente de sua concentração.

Houve diferença significativa sobre todas as demais características discutidas, conforme mostrado

TABELA 1. Análise de variância para as características avaliadas em plântulas de $L$. alba cultivadas em diferentes concentrações de BAP (mg L-1).

\begin{tabular}{lcccccc}
\hline $\begin{array}{c}\text { Fonte de } \\
\text { Variação }\end{array}$ & $\begin{array}{c}\text { Índice de } \\
\text { Sobrevivência } \\
(\mathrm{Pr}>\mathrm{Fc})\end{array}$ & $\begin{array}{c}\text { Número de } \\
\text { Folhas } \\
(\mathrm{Pr}>\mathrm{Fc})\end{array}$ & $\begin{array}{c}\text { Número de } \\
\begin{array}{c}\text { Brotos } \\
(\mathrm{Pr}>\mathrm{Fc})\end{array}\end{array}$ & $\begin{array}{c}\text { Comprimento } \\
\text { de Brotos } \\
(\mathrm{Pr}>\mathrm{Fc})\end{array}$ & $\begin{array}{c}\text { Massa } \\
\text { Fresca } \\
(\mathrm{Pr}>\mathrm{Fc})\end{array}$ & $\begin{array}{c}\text { Massa } \\
\text { Seca } \\
(\mathrm{Pr}>\mathrm{Fc})\end{array}$ \\
\hline BAP & $0,1240^{\mathrm{NS}}$ & $0,0000^{*}$ & $0,0035^{*}$ & $0,0000^{*}$ & $0,0209^{*}$ & $0,0077^{*}$ \\
$\mathrm{CV}(\%)$ & 15,40 & 16,65 & 20,76 & 15,35 & 42,89 & 32,12 \\
\hline
\end{tabular}

\footnotetext{
${ }^{*}$ significativo a $5 \%$ de probabilidade, Ns não significativo.
} 
na Tabela 1. Maior número de folhas $(64,0)$ foi observado na ausência de BAP (Figura 1), sendo que o aumento na concentração desta citocinina promoveu decréscimo na quantidade de folhas formadas. Resultado semelhante foi obtido por Villa et al. (2005), trabalhando com amoreira-preta, que observaram queda no número de folhas com aumento das concentrações de BAP. Isso pode ser atribuído ao fato de este regulador de crescimento estimular a formação de maior número de brotos, porém, de tamanho reduzido, apresentando menor número de segmentos nodais e folhas. Resultado diferente do encontrado por Blank et al. (2008) com a espécie Lippia sidoides (Cham.) que apresentou maior número de folhas na concentração de $4 \mathrm{mg} \mathrm{L}^{-1}$ de BAP.

A proliferação de brotações foi estimulada pelo aumento da concentração da citocinina (Figura 2), sendo o maior número $(4,0)$ observado utilizandose a maior dose deste regulador (BAP 1,5 $\mathrm{mg} \mathrm{L}^{-1}$ ). Para Lippia micromera (Schau.), variedade Helleri, melhores resultados de multiplicação ocorreram com
2,0 $\mathrm{mg} \mathrm{L}^{-1}$ de BAP em associação a auxina $(0,1 \mathrm{mg}$ $\mathrm{L}^{-1}$ de ácido naftalenoacético (ANA)) (Capote et al., 1999). A eficiência desta citocinina na multibrotação de plantas da família Verbenaceae foi reportada por Balaraju et al. (2008).

Em contrapartida, brotos maiores $(18,86 \mathrm{~cm})$ foram observados na ausência de BAP (Figura 3). O aumento nas concentrações desta citocinina reduziu significativamente o comprimento dos brotos. O efeito inibitório do BAP sobre a altura de brotos já foi reportada na multiplicação in vitro de macela (Diniz et al., 2003) e de videira (Lucas et al., 2006). Esses resultados podem estar relacionados ao fato deste regulador de crescimento não ser responsável em promover o alongamento de brotações.

Maiores massa fresca de parte aérea $(1,07$ g) foram observadas utilizando-se $0,5 \mathrm{mg} \mathrm{L}^{-1}$ de BAP (Figura 4). Provavelmente isso ocorreu devido às plantas conseguirem absorver mais água para seus tecidos nesta concentração de regulador e, portanto, incrementaram sua massa fresca. Em Lippia sidoides

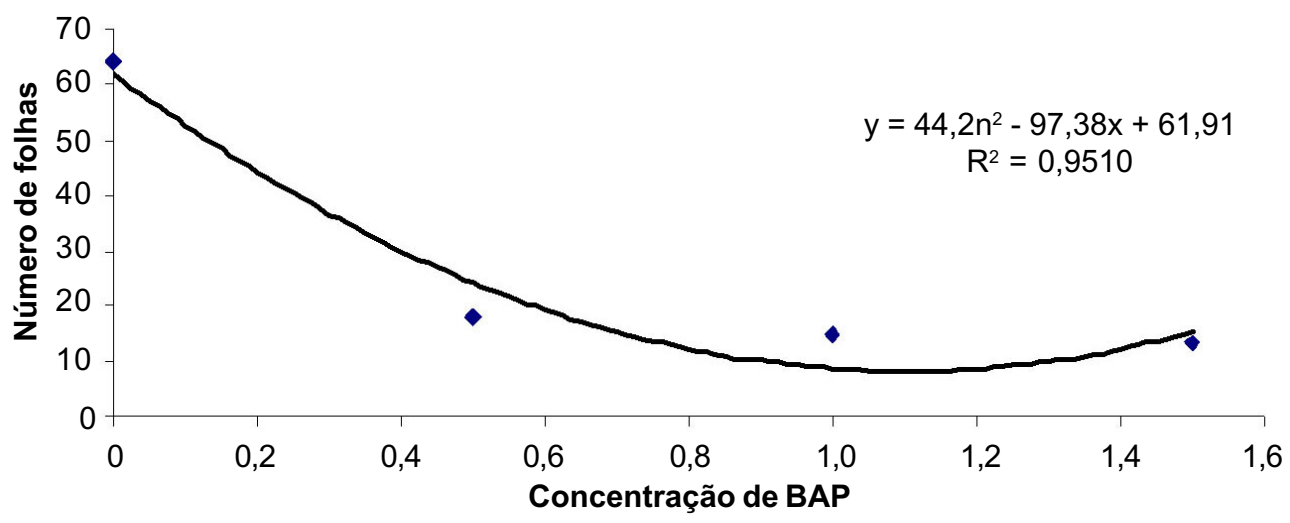

FIGURA 1. Número de folhas em plântulas de Lippia alba cultivadas em diferentes concentrações de BAP $\left(\mathrm{mg} \mathrm{L}^{-1}\right)$.

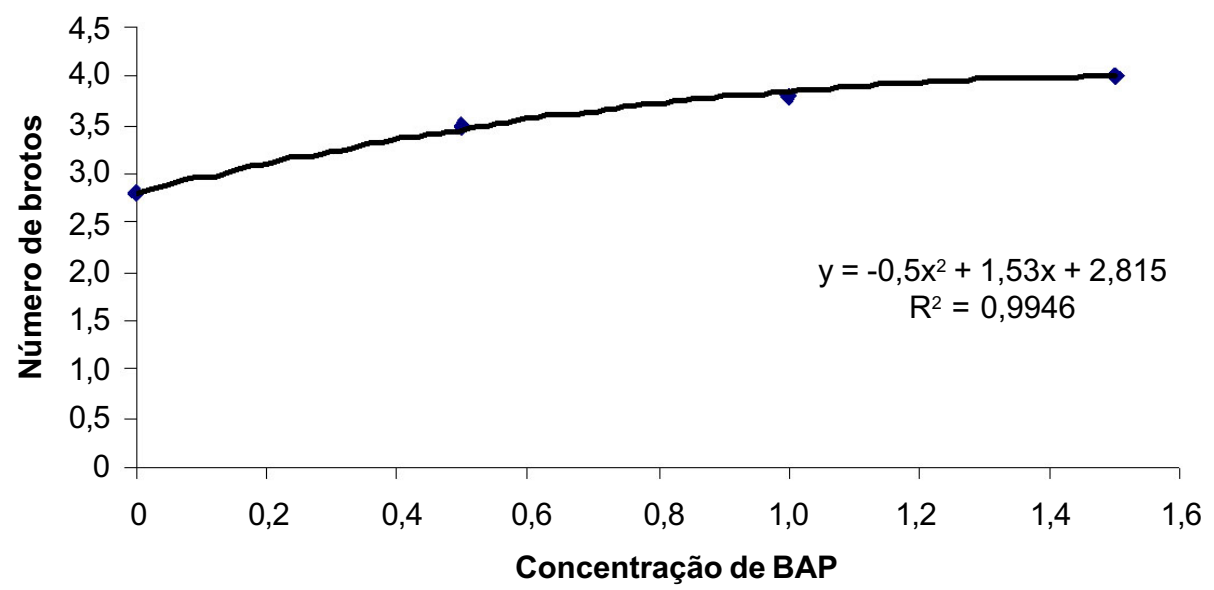

FIGURA 2. Número de brotos em plântulas de Lippia alba cultivadas em diferentes concentrações de BAP (mg L-1). 


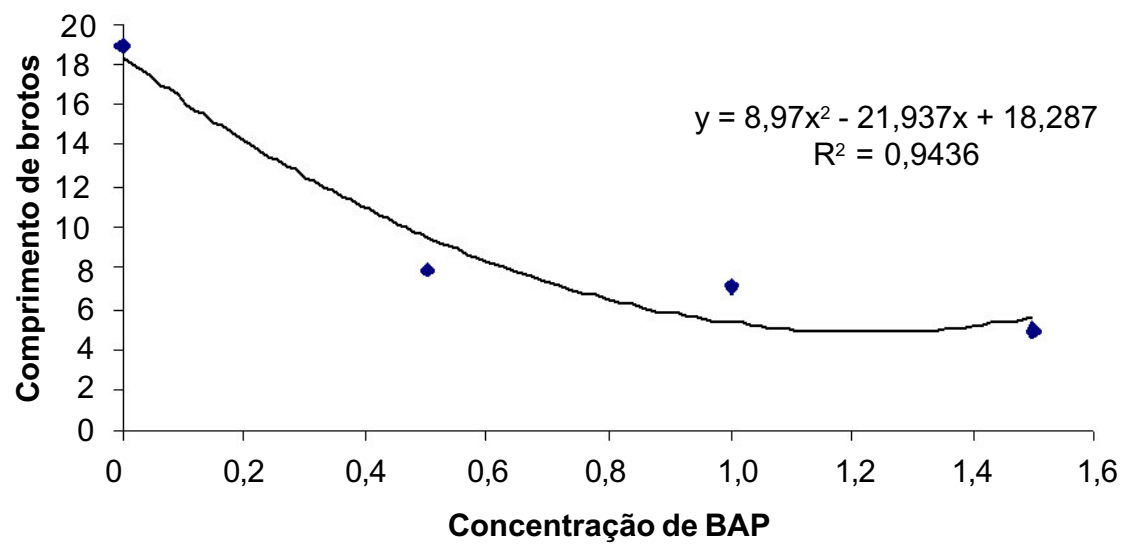

FIGURA 3. Comprimento de brotos $(\mathrm{cm})$ de plântulas de Lippia alba cultivadas em diferentes concentrações de $\operatorname{BAP}\left(\mathrm{mg} \mathrm{L}^{-1}\right)$.

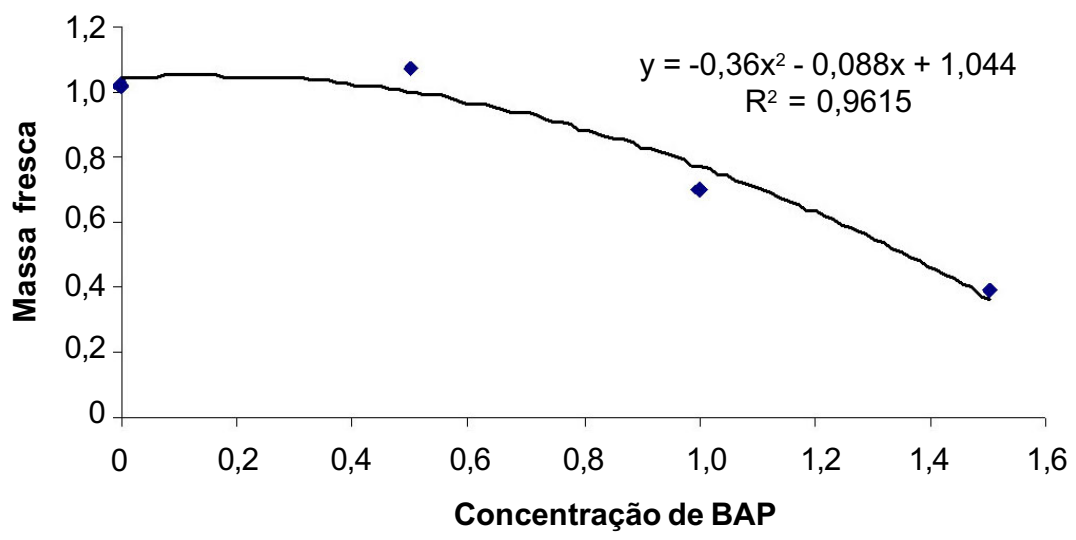

FIGURA 4. Massa fresca (g) da parte aérea de plântulas de Lippia alba cultivadas em diferentes concentrações de $\operatorname{BAP}\left(\mathrm{mg} \mathrm{L}^{-1}\right)$.

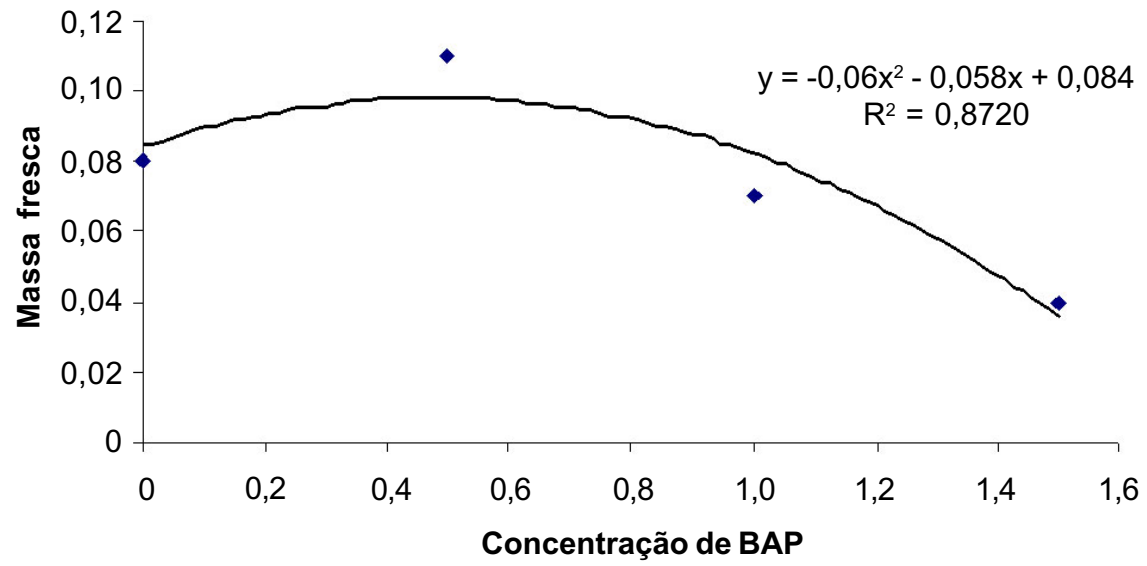

FIGURA 5. Massa seca (g) da parte aérea de plântulas de Lippia alba cultivadas em diferentes concentrações de $\operatorname{BAP}\left(\mathrm{mg} \mathrm{L}^{-1}\right)$.

(Cham.), testou-se diferentes reguladores de crescimento e concluiu-se que a concentração de $0,1 \mathrm{mg} \mathrm{L}^{-1}$ de BAP promoveu maior acúmulo de matéria fresca nas folhas dessa espécie micropropagada em meio de cultura MS (Costa, 2006).
A massa seca da parte aérea, que é a expressão do crescimento real da parte aérea, atingiu o valor máximo $(0,11 \mathrm{~g})$ com a utilização de $0,5 \mathrm{mg} \mathrm{L}^{-1}$ de BAP (Figura 5), à semelhança do ocorrido para a variável massa fresca. A partir desse ponto, o regulador de crescimento passou a inibir o 
desenvolvimento das plantas in vitro, apresentando decréscimo na massa seca.

Concluiu-se que a utilização de $1,5 \mathrm{mg} \mathrm{L}^{-1}$ de BAP promove a multiplicação in vitro de Lippia alba.

\section{AGRADECIMENTO}

Os autores agradecem a Coordenação de Aperfeiçoamento de Pessoal de Nível Superior (CAPES) pelo auxílio financeiro recebido.

\section{REFERÊNCIA}

BALARAJU, K. et al. Micropropagation of Vitex agnuscastus (Verbenaceae) - a valuable medicinal plant. In Vitro Cellular and Developmental Biology Plant, v.44, p.436-41, 2008.

BLANK, A.F. et al. In vitro establishment of pepperrosmarin nodal segments. Horticultura Brasileira, v.26, p.255-8, 2008.

CAPOTE, A. et al. Micropropagación y regeneración de plantas in vitro de oreganillo Lippia micromera Schau. Revista Del Jardín Botánico Nacional, v.10, p.13942, 1999.

COSTA, A.S. Sustentabilidade da produção de alecrim-pimenta (Lippia sidoides Cham.): micropropagação visando à conservação in vitro. 2006 . 70p. Dissertação (Mestrado em Agroecossistemas) Universidade Federal de Sergipe, São Cristóvão.

COSTA, A.S. et al. Estabelecimento de alecrimpimenta in vitro. Horticultura Brasileira, v.25, n.1, p.68-72, 2007.

DINIZ, J.D.N. et al. Ácido giberélico $\left(\mathrm{GA}_{3}\right)$ e $6-$ benzilaminopurina (BAP) no crescimento in vitro de macela [Egletes viscosa (L.) Less.]. Ciência e Agrotecnologia, v.27, n.4, p.934-8, 2003.

ERIG, A.C.; SCHUCH, M.W. Micropropagação fotoautotrófica e uso da luz natural. Ciência Rural, v.35, n.4, p.961-5, 2005.

FERREIRA, D.F. Sisvar 4.3: sistema de análises de variância para dados balanceados: programa de análises estatísticas e planejamento de experimentos. Lavras: UFLA/DEX, 2000.

GUPTA, S.K. et al. In vitro micropropagation of Lippia alba. Current Science, v.81, n.2, p.206-10, 2001.

JULIANI JÚNIOR, R. et al. Micropropagation of Lippia junelliana (Mold.) Tronc. Plant Cell, Tissue and Organ Culture, v.59, p.175-9, 1999.

LUCAS, M.A.K. et al. Multiplicação in vitro do porta-enxerto de videira Paulsen 1103 com benzilaminopurina e ácido indolbutírico. Plant Cell, Culture and Microprogagation, v.2, p.29-34, 2006.

LUCAS, M.A.K. et al. Micropropagação de violeta-africana (Saintpaulia ionantha Wendl.): efeito da benzilaminopurina na multiplicação. Ciência e Agrotecnologia, v.31, n.5, p.1380-5, 2007.

MARTINS, E.R. et al. Plantas medicinais. Viçosa: UFV, 2000. 178p.

MING, L.C. Influência de diferentes níveis de adubação orgânica na produção de biomassa e teor de óleos essenciais de Lippia alba (Mill.) N. E. BR. Verbenaceae. 1992. 206p. Dissertação (Mestrado) - Universidade Federal do Paraná, Curitiba.

MURASHIGE, T.; SKOOG, F. A revised medium for rapid growth and bioassays with tobacco tissue cultures. Physiologia Plantrarum, v.15, n.3, p.473-97, 1962.

NARGIS, A. et al. A study of plant growth hormones on in vitro clonal propagation of fever tea (Lippia javanica): a medicinal shrub. American-Eurasian Journal of Sustainable Agriculture, v.4, n.3, p.274-9, 2010. PIMENTA, M.R. et al. Floração, germinação e estaquia em espécies de Lippia L. (Verbenaceae). Revista Brasileira de Botânica, v.30, n.2, p.211-20, 2007. PEIXOTO, P. et al. In vitro propagation of endangered Lippia filifolia Mart. and Schauer ex Schauer. In Vitro Cellular and Developmental Biology Plant, v.42, n.6, p.558-61, 2006.

RAO, G.P. et al. Studies on chemical constituents and antifungal activity of leaf oil of Lippia alba (Mill.). Indian Journal of Chemical Technology, v.7, n.6, p.332-35, 2000.

VILLA, F. et al. Multiplicação in vitro da amoreira-preta 'ÉBANO' em diferentes concentrações de meio MS e BAP. Ciência e Agrotecnologia, v.29, n.3, p.582-9, 2005.

Rev. Bras. PI. Med., Botucatu, v.14, n.esp., p.149-153, 2012. 